This is a post-peer-review, pre-copyedit version of an article published in Journal of Outdoor and Environmental Education. The final authenticated version is available online at: https://doi.org/10.1007/s42322-019-00041-7

Please cite this article as: Zeivots, S. (2019). Escaping to nature to learn: emotional highs in adult learners. Journal of Outdoor and Environmental Education. 1-18. https://doi.org/10.1007/s42322-019-00041-7

\title{
Escaping to nature to learn: Emotional highs of adult learners
}

\begin{abstract}
This study examines the role of nature in relation to emotional highs in adult learning. Hermeneutic phenomenology was used as an overarching methodology and contained both descriptive and interpretive elements. The methodology enabled access to an exploration of the phenomenon with further interpretation of the experiences of the 21 adults who participated in one of three outdoor learning courses. As a part of the findings, three emerging themes are discussed: nature as a sense of escape; learning in nature; and sense of therapy in emotional highs. The study found that nature profoundly affected the experiences of the participants and at times operated as a co-therapist to foster unique learning opportunities. Nature was seen by participants as a learning environment where temporary escape from one's customary life is possible. Sense of escape in the education settings was found beneficial because it enabled participants, as learners, to get away from life's usual distractions and routines, and with available time and permission to reflect - to become someone else. This in turn positively affected learning capacity as participants re-connected with themselves without being bound to familiar and taken-for-granted practices.
\end{abstract}

Keywords: nature, emotional highs, outdoor learning, wilderness, therapeutic, positive emotions

\section{Relationship with nature}

Never in history have humans spent so little time in physical contact with nature

(Kesebir \& Kesebir 2017). In the past 60 years there has been a shift in nearly every aspect of humans' relationships with nature, particularly in regard to loss (Moran 2016). This transition, among other things, can be linked to worldwide increases in urbanisation (Heilig 2012) and changes in human functioning due to decreased exposure to nature (Kotabe, Kardan, \& Berman 2017), often leading to an increase in mental disorders (Patel, Flisher, Hetrick \& McGorry 2007).

Other streams of literature are more critical of the human-nature relationship. 
Derby, Piersol and Blenkinsop (2015) question the notions of "nature", "wilderness", and "wildness", and how these are constructed in literature. They suggest that nature in cities, for instance, is different from nature encountered in less urbanised areas, and thus should not be mistaken as a synonym for the outdoors. What further prods this narrative is that nature, according to Miles (1990), is "both a physical and conceptual space" (p. 325). In some cases it is an idea rather than a well-defined concept.

In this study, nature is seen as including, but not limited to, environments encompassing general outdoor settings that are not under constant human surveillance and control, and where non-human life continues somewhat unhindered (Smith 2007). This conceptualisation encompasses both living and non-living components of ecosystems at a physical and perceptual level. In this paper, some of the participants used "nature," "wilderness" and "outdoors" interchangeably, and thus, the notions here are seen as inter-related along a spectrum rather than as conflicting or discrete concepts. In this paper, nature is understood as a similar notion to wilderness, and, as a point of difference, "nature" encompasses more human aspects, artefacts and practices.

Research suggests that exposure to nature has multiple benefits. Regular nature visits can predict higher happiness, the sense of a worthwhile life (White, Pahl, Wheeler, Depledge \& Fleming 2017), improved mental health (Buckley \& Brough 2017), and other benefits for health, memory and emotions (Cox, Shanahan, Hudson, Fuller, Anderson, Hancock \& Gaston 2017; Kotabe et al. 2017). The growing number of such studies adds to the understanding of the benefits of exposure to nature. However, it also reveals complexities around the research in the area.

Natural and urban settings, for example, have often been seen as antithetical. This standpoint has been criticized as failing to incorporate the complexities of human dimensions into wilderness literature, especially those of urban settings (Gandy 2016). 
Urban wilderness, for instance, has become a regular item on the urban planning agenda with various viewpoints being expressed, ranging from sadness for lost experiences of nature to pressing for a plethora of wild areas being created and transformed in dense cities. On the other hand, large "wilderness" areas have been dwelt in for millennia by Indigenous peoples, showing that human impact is clearly present in areas often portrayed as inhabited only by non-humans (Kowarik 2018; Gammage 2011). Further complexity can be seen in relation to what we mean by "nature." Some studies claim stress recovery through the practice of merely facing an image of trees ( $\mathrm{Jiang}, \mathrm{Li}$, Larsen \& Sullivan 2016). Although this study does refer to nature in urban settings, the practice can position nature as re-presentation, in contrast to a concrete physical encounter "in" nature. These complexities suggest that understanding the benefits of encountering nature is rather more difficult than it may at first appear.

This study is concerned with the role nature plays in educational environments. There is little, predominantly theoretical, research on how nature affects learning (McKenzie 2000; Russell et al. 2013). According to Rutko and Gillespie (2013), research studies find it challenging to explain and articulate why learning outdoors is helpful. They observe that some researchers (e.g. Ungar, Dumond, \& McDonald 2005) note the positive outcomes of outdoor education, for example: lower depression rates (Christensen, Holt, \& Wilson 2013), increased subjective wellbeing, mindfulness, selfefficacy (Mutz \& Müller 2016), and personal and social development (Scrutton \& Beames 2015); and yet these benefits are not necessarily exclusive to nature. In fact, the practice of learning in nature is often grounded in assumptions, resulting in an incomplete picture of what makes it effective (McKenzie 2000). Based on this, the rationale of "why to learn in nature?" still poses more questions than answers, and requires more in-depth and empirical research. 


\section{Learning in nature}

Learning in nature often stands out by providing naturally occurring consequences and "rules" that are more likely to be accepted as "fair game" among learners (Kimball \& Bacon 1993). These rules can be viewed not only as powerful and authentic, but are thought to encourage self-awareness and self-responsibility (Walsh \& Golins 1976). Learning in nature often stands out by providing a sense of justice and impartiality, thereby diminishing fragmentation and confusion (Bacon 1983). In some cases, it is considered beneficial to therapeutic practices (Conlon, Wilson, Gaffney \& Stoker 2018, Fernee, Gabrielsen, Andersen \& Mesel 2017). Learning in nature plays a vital role in the general wellbeing of the individual, both for adult learners (Lemke 2018) and youth (Norton, Tucker, Russell, Bettmann, Gass \& Behrens 2014), particularly through its rehabilitative and therapeutic properties. Inherent in this process are components of the natural environment that embrace aspects such as risk, challenge, and uncertain outcomes that can be influenced by the learner. Ewert and Voight (2012) suggest these types of learning experiences strengthen and build empowerment, resilience, sense of achievement and restoration, which all appear to contribute to, and derive from, the therapeutic experiences.

Belief in the beneficial effects of learning in nature can be seen in the growing number of forest schools, especially in the Nordic countries (Norðdahl \& Jóhannesson 2016). Although forest schools are at times exposed to criticism (Leather 2018), commonly grouped in policy-, people-, place- and resource-related challenges (Edwards-Jones, Waite \& Passy 2018), the outdoor environment - learning in nature is often perceived to provide enriching learning experiences. This builds upon an understanding of nature as a "third educator" (Torquati \& Ernst 2013). The concept of 
the third educator is based on the personification of nature, which can be seen as active and responsive, and hold endless possibilities for learning - to explore, observe, interact and play - across all curricular domains.

\section{Adult learning in nature: emotional highs}

Much of the research conducted in outdoor education has occurred with children and adolescents (Huynh \& Torquati 2019). An extensive literature review focused on outdoor education programs for adolescents (Becker, Lauterbach, Spengler, Dettweiler \& Mess 2017) found that these programs can advance students' physical, psychological, social and learning skills. The literature related to adult participation in outdoor education is limited, but growing (e.g., Hickman, Stokes, Beard \& Inkster 2017). Extending the work of Finlay, Franke, McKay and Sims-Gould (2015), Loeffler (2018) observes that the literature on how nature contributes to the physical, emotional and learning dimensions of adults is sparse, and suggests it is critical to further examine the connections between nature and learning in nature across the lifespan.

This paper arises from an extensive research study focused on outdoor education. It expands on an unanticipated finding of the study, specifically the role of nature in relation to emotional experiences. Nature is an exceptional learning environment in that it can be considered a trigger to strong positive emotional experiences. Influenced by the literature of Rantala and Määttä (2012) and Briscoe (2012), I have called these experiences "emotional highs," referring to the "inner deep satisfaction a learner experiences when they have absorbed something meaningful" (Zeivots 2018, p. 275). The study mentioned did not investigate what nature actually does in this process, although its crucial role is implied. This paper extends the inquiry and explores nature as a learning space for emotional highs to emerge. 
The state of literature that focuses on the relationship between learning, nature and emotional highs can be described as what Ewert (1983) called an "educational black box" in the sense that "we know something works, but we don't know why or how" (p. 27). This paper is concerned with advancing understanding of the relationship between nature, learning and emotional highs in order to open up this black box.

\section{Hermeneutic phenomenology}

Hermeneutic phenomenology was used as the study's overarching methodology. Noting that this methodology comprises two terms, it is important to highlight how they come together to offer something beyond what each may comprise separately. On the one hand, phenomenology focuses on the lived experience of humans and their perceptions (Langdridge 2007), and on the other, hermeneutics involves interpretation and application of their lived experience (Schmidt 2016). Hermeneutics goes beyond a pure description of concepts and looks for meanings embedded in practices (Lopez \& Willis 2004). In educational research, combining phenomenology and hermeneutics helps not only to understand the lived experience of learners, but also assists with clarifying the conditions that lead to some level of understanding (Holroyd 2007).

Hermeneutic phenomenology is founded in the ontological view that researching lived experience is an interpretative process (van Manen 2016) and movement away from the positivist frameworks that view the reality being "out there" (Laverty 2003). Some researchers (e.g., Plager 1994) note that the interviewee's perception of reality can become distorted, as the meaning documented by the researcher is invariably interpreted. Van Manen (1997) states that having an encounter with the phenomenon does not necessarily indicate one can formulate it in words. Rather than an interpretation of the reality of one or the other, the reality is formed by both the subject and the researcher. In this way, the eventual text is a result of an intersubjective and 
contextual situation. This study aligns with this approach and regards the participant and researcher as co-participants of the sense-making process.

A deliberate decision was made to approach adult experiences of emotional highs in nature experientially, in a phenomenological sense. In other words, to attempt to stay with these shared experiences themselves rather than positioning them in specific ways prior to thinking about them. This was to allow features of this phenomenon - adult experiences of emotional highs in nature - to be illuminated without utilising pre-defined models (such as models which categorise emotions in certain ways) that may pre-judge these experiences and hence limit interpretative opportunities.

\section{The participants and courses investigated in the study}

The broader study from which this paper is drawn focused on adults' experiences during extended leadership courses, which had significant outdoor components. Three courses were investigated in this study, all held in Australia. Outward Bound (OB) conducted two of these courses, which were different (OB1 and OB2), and Collective Possibilities (CP) conducted the third.

These courses were chosen because they were experientially orientated in their pedagogy. Experiential learning courses were selected because they typically address the learners' physical, cognitive, emotional and value aspects in ways that may provoke a wide spectrum of emotional experiences. These courses involved outdoor activities and were known for regular emotional highs and lows. For the analysis underpinning the findings shared in this paper, learners and courses were selected based on participants' exposure to, and frequency of, emotional high experiences. Ideally, the phenomenon emerged several times and in multiple ways to provide enough suitable experiences for participants to reflect upon. 
All three courses were leadership-themed, involved active and reflective activities, and aimed to foster personal growth, self-actualisation and social skills. These aspects were the premise of a larger study (Zeivots, 2015). Connection with nature was not a primary goal of the study, however the findings and their profound link to nature has inspired the focus of this paper.

All of the courses were residential (OB1 - eight days, OB2 - seven days, $\mathrm{CP}-$ four days), and each had an equal number of days outdoors and indoors. The outdoor aspects of the courses involved learning activities conducted in wilderness areas; in the OB courses the participants hiked through a remote national park both day and night.

The courses all shared the philosophical position that lived experience within the course was an integral part of the learning that might be achieved. The outdoor courses were diverse and included activities like hiking, abseiling, crossing rivers, sleeping outdoors in sleeping bags and problem solving tasks. While some activities were physical, others involved reflective practices, such as the Value Path activity in OB1 and $\mathrm{OB} 2$, where participants spent around two hours walking alone through a national park with minimal guidance, passing interactive checkpoints and reflecting. At one checkpoint, "you had to draw a picture of yourself," Robert (OB1) shared; more specifically, "you had to lie on the ground and then draw the outline of your body." Picking up this life-sized depiction, looking at oneself and reflecting on how one wanted to be remembered, triggered some insights as well as emotions; most of them eye-opening and meaningful.

The numbers of adult learners in the courses were as follows: twelve in OB1, a course for Australian rural leaders; eight in OB2, a course for early career managers and leaders; and eighteen in $\mathrm{CP}$, a course for new team leaders and supervisors from local governments in Victoria. This study focused on 15 participants selected on the basis of 
the number and variety of strong emotions evoked during a course; an average of five participants per course. The selected number was suitable for hermeneutic phenomenological study to achieve the necessary critical mass of experiences and equally to generate opportunities to engage with individual narratives. The sample was diverse in gender and age; there were similar numbers of women and men, their ages ranged from mid-twenties to early seventies, and they came from various Australian states. The respondents volunteered to participate in the study after their course was completed and gave informed ethics consent. The following sections will refer to participants' lived accounts using personal pseudonyms and course abbreviations in brackets.

\section{The two-stage design of the study}

This study followed a two-stage research design. The first stage - a short participant questionnaire - was used to briefly ascertain emotional experiences of all participants during the course. Facilitators of the three courses invited attendees to participate in the voluntary one-question survey with an option to leave their contact details, if they agreed to participate in the follow-up interview. By selecting specific emotions experienced, for example feeling excited, fantastic, satisfied, bored and overwhelmed, the first stage was used to further select participants who had experienced significant emotions during the courses. The researcher then selected participants who had experiences of the phenomenon - emotional highs in nature - and invited them take part in the next stage.

The second stage involved in-depth interviews with invited participants who agreed to continue with the study. These participants were asked to reflect on their lived experience within the course. They were asked to construct an emotional graph (Figure 1) that focused on their emotional experiences throughout the course. The more positive 
an experience, the higher its position on the emotional graph, while less positive and perhaps negative experiences appeared lower on the graph. Most graphs included several peaks and lows across the course. Learners were invited to reflect on up to four

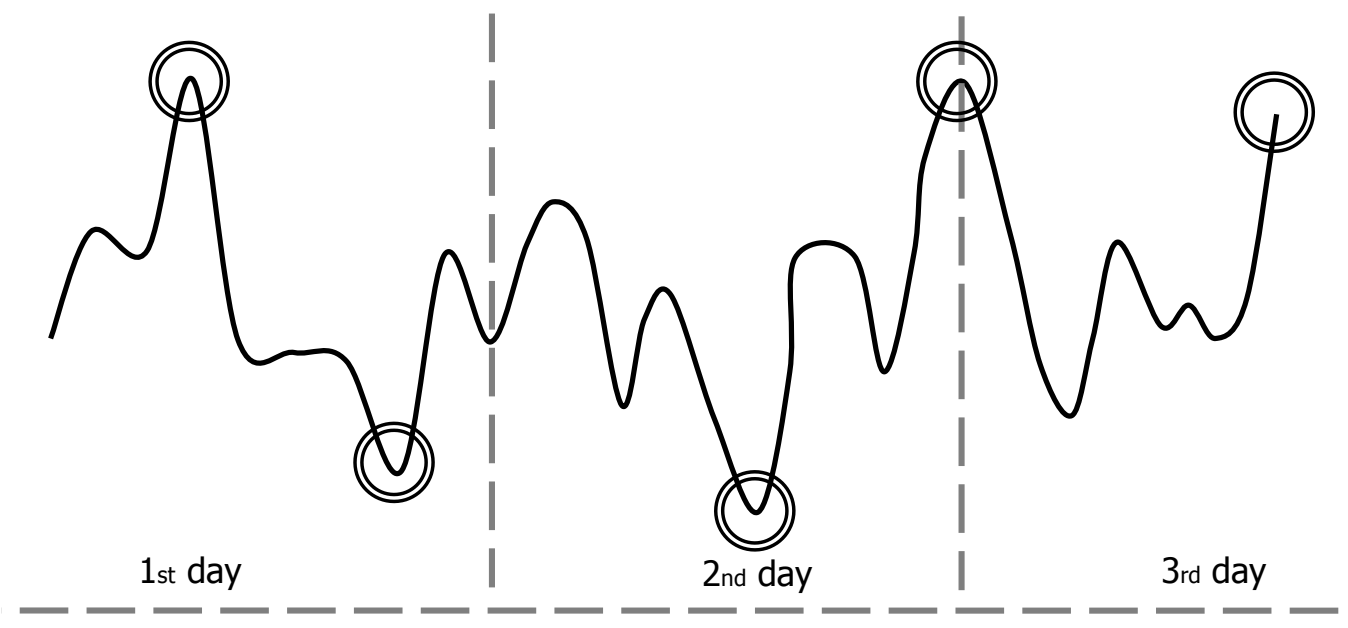

Figure 1. Example of emotional graph (Zeivots 2016).

of the higher peaks in the chart. This was followed by triggering sense-making questions, for example: "what made you feel good in this [emotional high] moment?" and "what are the key ingredients of this experience?" In this way, the participants were encouraged to reflect on their lived experiences in the form of rich narratives.

Participants were further invited to engage with making sense of their experiences as per hermeneutic phenomenological methods (Smith, Flowers \& Larkin 2009). The experiences that discuss, and relate to, nature were selected for the purposes of the paper.

\section{Interpretative phenomenological analysis}

To examine the data, a six-step approach was used based on interpretative phenomenology analysis (IPA) (Smith, Flowers \& Larkin 2009). IPA is a qualitative research approach that has significant roots in phenomenology, hermeneutics and idiography (Pietkiewicz \& Smith 2014). IPA is a step away from what some call 
"genuine phenomenological enquiry" (van Manen 2017) and is neither used to gather "true" or "one-size-fits-all" facts, but instead to focus on making sense of participants' unique experiences and to highlight their meaning-full accounts (Larkin, Watts \& Clifton 2006). The six-step approach involved: (1) reading and re-reading, (2) initial noting, (3) developing emerging themes, (4) searching for connections, (5) moving to the next case, and (6) looking for patterns across cases. The sequence of steps is recommended rather than strictly fixed. At times data analysis required linking several steps simultaneously, especially in developing emerging themes. The main goal of IPA is to give appreciation to each individual participant's account and illuminate themes that emerge. For this reason, IPA samples are typically small to allow detailed and rich analysis (Pietkiewicz \& Smith 2014). It is a particularly useful analysis approach for examining topics which are complex, ambiguous and emotionally laden (Smith \& Osborn 2015). Consistent with the focus of this paper, the accounts and data that relate to nature, learning and emotional highs were selected and analysed.

\section{Findings}

The fundamental focus here is on providing an in-depth understanding of the relationship between nature, learning and emotional highs - satisfying and meaningful participant learning experiences. As a part of the analysis, this section will discuss three patterns that emerged across the participants' narratives, focusing on their course experiences. The narratives will be further investigated in the discussion section. The themes are: nature as a sense of escape; learning in nature; and sense of therapy in emotional highs.

\section{Nature as a sense of escape}

The first theme to emerge is that nature can provide a sense of temporary escape for 
learners. Approximately half of the participants admitted that they had been stagnating in life before entering the course. "You're stuck in a day to day routine. Not really going anywhere kind of scenario," Giuseppe (CP), a new team leader in a local Victorian government, reflected. Although the courses did not target specific adult learners with life challenges, several participants explicitly or implicitly indicated that travelling to a remote natural place allowed them to go away and have a break from their lives. Giuseppe (CP) observed that "the country was good. [It's] always nice to get out of the city. At that point you are not thinking about your life or that sort of thing."

Learning in nature was often referred to, and experienced as, an escape.

Participants frequently referred to the course as a magical tool that removed their outer life, daily routines and social roles; at least temporarily. Thomas, a rural leader in OB1, revealed that, "[be]cause I do go a hundred miles an hour, sometimes I just need to sit back. That was one thing why I really loved that ... I was walking slowly. I wasn't time bound." The idea of escape here appears as a metaphor for changing an environment or being away from a busy lifestyle and responsibility.

Altogether, three versions of escape came through the interview accounts. First, being in nature was seen as a temporary release from work and home responsibilities. When out in nature, you do not have to worry "whether the reports are in or contracts done" (Ryan OB1) or "[you've] got to fix that door" (Robert OB1). Although work and/or family were important for most participants, temporarily leaving them appeared beneficial. Learning in nature provided an opportunity to get away - "away" used almost as the magic tool that erases physical and perceptive boundaries. "Over the last two years work kept me very busy. I wasn't really focused on what has happened to me outside of work. What I've done... How I've been able to come out of it," revealed Thomas (OB1) for whom such experiences were "pretty special." 
Second, nature was often seen as an escape from modern conveniences and comforts. Participants referred to being removed from showering, changing clothes, spraying deodorant (Thomas OB1), having make-up and high heels (Helen OB1), and handing over mobile phones (Susan OB2). While for some, escaping familiar surroundings and comforts was challenging, others perceived it as soothing and rejuvenating. Thomas (OB1) said it was a "really great experience - without the interruption from the outside world, mobile phones, emails, and all that sort of stuff."

Participants frequently described the arrival in, and departure from, nature as a change of environment, people, routines and experiences. Most participants noticed the difference: for some the change was slight, for others - distinct. Leaving an outdoor course and returning to an urban environment was referred to as being "back in the reality" (Helen OB1), in "real life" (Victoria OB2), and "in the metropolitan area, having a shower and other comforts" (Ryan OB1). In contrast to the urban settings, nature appeared as a space where many layers of comfort, both wanted and unwanted, were stripped away.

Third, learning in nature came across as escaping one's accustomed life. In contrast to the first two types of escape, this was regarded not solely as a physical escape but rather as a perceptual one. In many cases it referred to the parts of the learner's life that were troublesome and dissatisfying. Escaping something in one's life differed from case to case and included being away from one's low self-esteem and adopted role in the family (Caitlin OB1), day-to-day problems on one's mind (Kirra OB1), and long drawn out quarrels (Leanne CP, Diane CP). In Caitlin's (OB1) case, temporarily leaving her accustomed life and work routine was so pleasant she said she did not wish to return to her "real life." 
These types of escape illustrate that temporarily being removed from one's everyday life can be worthwhile, especially for the learning process. The escape can help to clear the mind, assist with seeing things differently and allow therapeutic experiences to emerge. Robert (OB1) observed, when learning "in the bush [an Australian term for forest] you can actually remove yourself from who you are and take on extra challenges." Kirra (OB1) and Caitlin (OB1) emphasised that there should be more learning opportunities available in nature, implying their willingness to both temporarily escape their lives and learn in outdoor settings. Overall, nature was portrayed as something that adds to learning by subtracting unhelpful familiar contexts; these could be put aside during the outdoor courses.

\section{Learning in nature}

Learning in nature played an important role in affecting emotional highs. The wide spectrum of elements - trees, mountains, valleys, boulders, wild animals, to name but a few - seemed to form an integral part of the experience.

The number of references to nature differed significantly from course to course. They were abundant in the narratives from the two OB courses and occasional in accounts of CP. In several cases, being outdoors appeared in rich descriptions of learning settings and novel experiences, like "driving into the country is good; always nice to get out of city" (Giuseppe CP), "watch the kangaroos" (Robert OB1), and "woke up with frost all over" (Thomas OB1). Richard (OB2) talked about his emotional high that was filled with features of being in nature: "comfortable just to really be there... with wombats out, with kangaroos, the river."

In both $\mathrm{OB}$ courses participants spent on average four days indoors and four days outdoors. During interviews, the OB participants were invited to indicate the days with richer emotional high experiences. Without exception, they mentioned the days 
that were spent outdoors. This choice, according to the participants, did not require any effort; it seemed obvious. Kirra (OB1) drew some contrasts between indoor and outdoor environments: "Being outdoors is wonderful. I like to light a fire, I like to go bushwalking ... Then we came in for the next four days. I didn't like it as much." During the indoor activities, participants mostly reflected on outdoor activities and through group work and role plays applied them to their personal and professional environments.

In the $\mathrm{CP}$ course the first two days took place indoors and the remaining two days outdoors. The arrangement for OB courses was reversed - first half was held outdoors, the second indoors. As with the OB participants, the $\mathrm{CP}$ participants interviewed said the outdoor days were filled with the most emotional highs. While one may argue that the beginning or the end of the course is more favourable for the emergence of emotional highs, this study found that the likelihood of the emotional highs is stronger during outdoor events, regardless of their scheduling.

According to many participants, learning in nature was exciting and engaging. For example, when Caitlin (OB1) was asked how she might replicate the emotional high experiences she had in the course, she said, to enjoy her learning "I have to go outside." Similarly, Kirra (OB1) admitted, "[in the] first four days what I enjoyed the most was to be outside." Ryan (OB1) added that learning in nature has "that genuine excitement." These cases do not seem to relate to any specific action or feature; rather they refer to nature in a holistic sense.

Some participants said they would prefer to learn like this outside the course settings, back in their regular lives. Kirra (OB1) was highly impressed by the course experience. In fact, she shared plans to organise a similar course for her working team. This course would first focus on doing, followed by reflection. According to Kirra, to 
replicate successful learning, "some of those components would be camping. I don't know how much of that would be in the classroom. Maybe out in the wilderness... I would like to learn like that all the time." Similarly, Alison (CP) said that learning outside the city and away from work affects oneself: "I enjoy that opportunity to learn. Wow this is great! You don't learn like this at work."

Nature comes across as a rich provider of unknown experiences for adult participants to face. Outdoors, according to participants, provides a wide range of opportunities and challenges, including getting out of their comfort zone, becoming exhausted and having limited distractions from the world. They could not predict what might await them over the next mountain or what the weather would be like. For some, these unknowable situations were powerful emotional prompts and being in, as they call, wilderness, was associated with returning to the basics, physically and metaphorically. Living in open nature for a few days, including sleeping under the stars, was often perceived as refreshing and perspective changing. That included new insights about oneself, others and the world. Martin (OB1), who comes from a tropical island in the far north of Australia, found that going to mountainous and cool surroundings at the end of autumn was a significant shift of environment:

The biggest shock was the change in temperature. It went from +29 to -3 . That automatically showed all my qualities ... To be honest it was a challenge in the mornings when you get dressed, get out of your sleeping bag (Ryan OB1).

The whole first day was to get everybody out of the comfort zone. We were surrounded by buildings, offices [in a big city] and then taken out into the wilderness ... Only two sets of clothes, we had to set up our own shelter ... We had to take control of everything ourselves out in the wilderness (Martin OB1).

Robert (OB1) showed an extraordinary affinity with nature. He found close ties with nature, sensing it as a "space" shared with ancestors: "[There] was a significant boulder 
in the mountain range, which I knew ancestors would have camped near." His accounts were abundant with descriptions of nature. Some were richer than others, showing how nature affected not only his values and attitudes, but his entire sociomaterial world:

We were outside at the top of the mountain. That was my highest [emotional high] because we were not climbing hills anymore. I was at the peak. I was looking around the tips and mountain ranges. Whichever way I looked, I was on top of the mountain (Robert OB1).

Nature in this case should not be conflated as equivalent to a medical fix or seen as the only aspect to trigger emotional highs. However, learning in nature appears to have affected the ways various situations were perceived; and at times challenging experiences were soothed by physically being in a remote outdoor environment. At one stage Kirra (OB1) was dissatisfied with facilitators for limiting her subjective freedom, which included telling her when to eat and when to go to sleep: "I don't like being told what to do. And it was cold. On that level I was frustrated." However, she instantly contrasted this with an upbeat remark linked to the environment: "But being outdoors in that time - was wonderful." It was followed by her affection for bushwalking and making a campfire.

\section{Sense of therapy in emotional highs}

The third emerging theme is the notion that emotional highs can be experienced as therapeutic. Although none of the courses specifically targeted therapy as a part of learning, some experiences seemed to involve therapeutic aspects. The foundations of this theme were based on the subjective participants' descriptions of emotional highs helpful, relieving, soothing and healing - all essential therapeutic characteristics.

There can be a wide epistemological spectrum between learning and therapeutic experiences. At one end there is the learner in an auditorium who would most likely not 
be seeking therapeutic help. At the other end there is the client seeing a personal therapist, hoping for assistance. Therapy, according to many participants, was perceived as being towards the middle of these extremes, and was used as a metaphor to describe experiences in the learning environment:

The questions and the structure that they [facilitators] put together, it makes you think in a certain way. Having the moment to do it with no distractions as well as being mentally and physically exhausted. Imagine that you had a therapist with you at that point and time asking you questions, you would come out with a lot more than you would like (Richard OB2).

While pushing oneself to one's mental and physical limits appeared significant (Zeivots 2015), therapeutic experiences often emerged through reflective practices. During and after the courses, as well as during interviews, participants frequently referred to reflection as a deeply personal, quasi therapeutic experience. Comments like "learning about yourself" (Kirra OB1) and "it is a very personal journey" (Susan OB2) were common in the narratives. Thomas, a busy banking manager in a regional city, claimed that the OB1 course was more about looking at himself than looking out. In his case an emotional high experience gave him insight into, and dedication to, what he would do in the next years. It was uncommon for Thomas, who was used to situations "at work" with "a very fast pace [environment] and you don't really have time to step back and think about the deeper things." Whereas within the course, he could "take that step back and see the other side of things."

While reflection is often seen as an internal process, numerous participants portrayed aspects of the therapeutic experiences of emotional highs by sharing reflections with others. An emotional high for Thomas (OB1) was the opportunity to "share my personal side with a group of people who wouldn't judge you" during the group work activities. Sharing reflections orally seemed to trigger something that made 
an experience powerful: "they were quite surprised to see this emotional side of me. It is quite hard to share a few tears when you're a bloke. It was good to have that response from a crowd" (Thomas OB1).

The main insight for Martin (OB1) was related to not only learning about himself, but also about others: “I realised that everybody's values are not wrong. How I see them is different from you. It showed me to be aware that your values are just as important as mine." Similarly, Robert (OB1) experienced a therapeutic and deeply social emotional high. During a group reflection after a long walk and collaborative activities, Robert realised that he had a "victim's mentality," meaning he regards himself as a victim of the negative actions of others: "That thing connected with me and made me come back and change something in my life." In this case social appears to resemble interaction that involves not solely other humans, but includes sociocultural and sociomaterial elements, like, values, identity and communication.

The three courses involved a wide range of experiences with abundance of the unknown, unfamiliar and unexpected, and often encompassed deeply emotional moments. A number of participants were explicit in saying that dealing with personal issues in a social context can be extremely challenging. Among the associated core experiences was the Value Path activity in both OB courses. Value Path is a solo activity "where you go through and connect with your values. What is important for you and what is not important" (Susan OB2). Participants would set off into the field in 15minute intervals and were not allowed to talk or walk with others.

The Value Path was followed by reflection among the group members. Participants' reflections included moments that were "exposing, confronting and embarrassing" (Helen OB1), and "I was crying, I was laughing" (Susan OB2). In each OB course there were some who wanted and some who did not want to share their 
experiences in the field. Those who did (the majority of surveyed participants) described their experience of having time to think about values as coming "out of their shells" (Thomas OB1). "I never really have opened up to such extent before," Thomas (OB1) revealed.

Most participants pointed to the Value Path as being an overwhelming emotional experience, especially when encountering deep and meaningful insights. A safe space was fundamental for discussing whatever came up or, in Richard's (OB2) words, "what happened, happened there.” In particular, emotional safety appeared among the key aspects that allowed therapeutic experiences to emerge. Despite Value Path being a tough task, many found it difficult to keep their responses to themselves: "It needed to be talked about," revealed Kirra (OB1). The paradox here was the difficulty experienced in giving "birth" to those emotions and let them out, yet simultaneously believing that it would be more painful not to let them out. Sharing in a few cases was seen as "liberating" (Susan OB2), "accepting" (Caitlin OB1) and highlighted as an integral feature of emotional highs. Safe and supportive social environments appeared to embrace aspects of remedying participants' existing problems.

Although mostly discussed metaphorically, some participants referred to emotional highs as therapeutic experiences. Richard (OB2) used the metaphor of seeing a therapist to describe his positive experiences within the course. According to Richard, emotional highs involved external facilitation, meaningful enquiring, and surprising, relieving insights. As well, the limited distractions from the outside world (discussed earlier), provided time to engage with activities mentally, emotionally and physically.

\section{Discussion}

The interrelationship between nature, learning and therapeutic experiences remains elusive and can still be easily taken for granted (Rutko \& Gillespie 2013). When 
illuminating learning benefits, scholars, as well as facilitators, seldom offer little, if any, mention of nature. Recognising that nature has inherent value in and of itself, despite often being intangible, is a fundamental step in demystifying the beneficial and therapeutic potential (Beringer 2004).

The findings of this study indicate that nature was widely represented in participants' reflections on their learning and their experiences of emotional highs. Based on learning program curricula and participants' accounts, the three courses studied included learning in nature. Without prompting, the narratives of participants in these courses included a high number of references to nature, outdoors and wilderness. While in some cases nature was used to depict the physical course environment, for most participants the notion was deeply entangled and embedded in learning experiences. It was also common to observe that learning in nature embraced therapeutic elements through liberating, accepting and remedying experiences, at least at a perceptual level.

Participants' accounts included iterative references to nature, for example via physical features such as mountains, rivers, stars, and animals such as kangaroos. As well, nature was experienced through outdoor activities, such as hiking, setting up a tent, building a fire, and sleeping under the open sky. At other times, references to nature moved beyond the physical to embrace elements such as values, beliefs, attitudes and cha(lle)nging routines. Nature can be the source of unfamiliar experiences that are different to those to which one is accustomed. While remote wilderness, home to the two OB courses, can be impressive, it can provide harsh realities and challenges. For some participants in the $\mathrm{OB}$ courses these were exciting, and for others they were uncomfortable, at times shocking. In any case, being in nature contributed to their learning and development. 
Some of these findings align with the broader discourse on learning in nature.

Harper, Gabrielsen \& Carpenter (2018) observe that wild places are unfamiliar and can challenge the learner practically and philosophically by invoking deep emotions. At times learning programs in nature promote disequilibria by exposing participants to unfamiliar spaces. Interestingly, nature itself offers a new recalibrating equilibrium and, according to Harper and colleagues, appears central to the construction of therapeutic experiences.

The less palpable aspects of nature emerge when considering a learner's sociocultural background. This study shows that aspects of nature afford learners opportunities to experience emotional highs and at times therapeutic experiences - both deeply meaningful and satisfying experiences. The interactions between nature and the learner can uniquely affect one's values and attitudes. Experiencing a sense of achievement, empowerment or restoration can appear as beneficial, soothing, and healing. Whilst outdoor education does not guarantee emotional highs, there is something perceptive and physical about nature that assists this possibility.

Learning in nature has become increasingly diverse, yet more specialised, especially in the areas that focus on therapeutic experiences. Pryor, Carpenter and Townsend (2005) observe the high regard for the natural environment within the broad areas of experiential learning, adventure learning and adventure therapy courses. Pryor and colleagues (2005) warn, however, that these areas should not be confused. Whilst outdoor learning attempts to re-engage learners with the natural environment, adventure therapy uses adventure as a medium with a regular focus on therapy.

Nature profoundly affects human outer and inner life (Beringer 2004), and the complexity behind the connectedness of all things shows that "going outside and going inside is really the same journey" (Smith 2005, p. 3). Remote outdoor learning 
environments allow nature to be co-therapist and foster unique opportunities for further learning and growth. Viewing learners as part of a broader structure and in relation to other people, landscapes, animals and plants can expand their verbal and cognitive ways of working and assist with widening the mind-body relationship (Berger \& McLeod 2006).

Learners typically enter learning settings with unique sociocultural backgrounds, values, attitudes and practices that can be both helpful to their development and thwart learning. The findings of this study suggest that being away from and temporarily escaping one's accustomed life can be not only pleasant, but also beneficial because escaping common routines can widen attitudes and expose one to diverse experiences. More particularly, an escape to nature can provide unique therapeutic experiences that assist learning. Participant Giuseppe (CP) called it "getting out of your experience to see it better."

This is similar to Albert Einstein's (2011) idea about leaving one's life to understand it: a person starts to live when he can live outside himself. Few are those who see with their own eyes and feel with their own hearts. Some routines and habits, often unconsciously, are blinding learners to other and potentially better possibilities. In other words, by being temporarily away from one's life, people can re-connect with themselves without being bound to familiar and taken-for-granted practices.

Morgan (2010) uses the notion of travel to describe the encounter process with otherness. Nature has the potential of triggering journey-like experiences and, thus, assist the learner to broaden their mind and practices. Similarly, a study on OB courses (Atchley, Strayer \& Atchley 2012) has found that a four-day immersion in nature and disconnecting from multi-media and technology increases the problem-solving and creativity performance by $50 \%$. The study highlights restorative cognitive advantages 
when learners can immerse themselves in nature. This however poses a question that requires further research - just how many of these outcomes are related to natural learning settings and not other elements, like being away from technology?

An essential aspect as to why temporary escape can be beneficial is that it allows the learner to become someone else. While it is believed that humans are always becoming (Singer 2018), this study shows that the potential to temporarily become someone else can lead to noticeable and meaningful change and affect their learning performance. Learners across the courses were temporarily removed from their normal lives, put together with strangers and asked to participate in demanding individual and group activities in a rather new environment. This affected them intensely.

Among the main changes they noticed was not having to be themselves, which provided opportunities to entertain new patterns of learning and being. Some participants admitted that being away from daily routines allowed them to achieve something significant that they could not reach in another way. Learning in the bush meant they were away from the usual distractions and problems, and with available time and permission to reflect on their life from a distance.

The importance of safety is widely discussed in educational literature. Adults need a safe environment to discover the value of their own learning (Wolfe 2006). Not only physical, but equally emotional and psychological safety should be considered (Cozolino and Sprokay 2006). Learners find it difficult to make connections if they are ashamed, may not respond quickly enough or feel stupid for giving a wrong answer. Ultimately, trust and supported environment in terms of learning are often associated with positive emotions (Zinn 2008) and emotional highs (Zeivots 2018). Safe learning will happen where there is the time, space and caring (Daloz 1990), and enough trust for learners to feel they can express and share even their partly formed ideas (Wolfe 2006). 
Nature should not be seen as a random or neutral learning space to escape to. It should be regarded for its unique physical features and limited human interference, as well as being an exciting place with an abundance of the unknown. Most participants acknowledged this: "It was a beautiful setting: just trees, hills, mountains and kangaroos. You're kind of prompted by what to think about" (Richard OB2).

\section{Conclusions}

Nature is seen as a favourable setting for various learning courses. Learners find nature not only exciting and engaging, but also a rich provider of unknown experiences. Nature is often perceived as a learning environment for emotional highs and therapeutic experiences to emerge. These experiences can come across as sense of achievement, experiences of restoration and empowerment and, thus, appear soothing and healing.

This study was concerned with the role of nature in relation to emotional highs in learning. As a part of the analysis, three patterns emerged: nature as a sense of escape; learning in nature; and sense of therapy in emotional highs.

This study showed that nature not only adds, but also subtracts elements during the learning experience. Nature can assist learners to temporarily escape accustomed practices and routines that at times thwart learning and development. In other words, nature can often be seen as a space of escape.

Three types of temporary escape were observed in the study: escape from work and home responsibilities; modern conveniences and comforts; and everyday life. For many participants these escapes were important for not only triggering emotional highs, but also for therapeutic dimensions. A benefit of temporary escape is that it allows the learner to become someone else. This study notes that becoming someone else can positively affect learning capacity. Other spaces also provide such dimensions, yet nature appears to have unique qualities for learners willing to embrace it. 


\section{References}

Atchley, R. A., Strayer, D. L., \& Atchley, P. (2012). Creativity in the wild: Improving creative reasoning through immersion in natural settings. PloS One, 7(12), 1-3.

Bacon, S. B. (1983). The conscious use of metaphor in Outward Bound. Denver, CO: Outward Bound.

Becker, C., Lauterbach, G., Spengler, S., Dettweiler, U., \& Mess, F. (2017). Effects of regular classes in outdoor education settings: a systematic review on students' learning, social and health dimensions. International Journal of Environmental Research and Public Health, 14(5), 1-20.

Berger, R., \& McLeod, J. (2006). Incorporating nature into therapy: A framework for practice. Journal of Systemic Therapies, 25(2), 80-94.

Beringer, A. (2004). Toward an ecological paradigm in adventure programming. Journal of Experiential Education, 27(1), 51-66.

Briscoe, F. M. (2012). Anarchist, neoliberal, \& democratic decision-making: Deepening the joy in learning and teaching, Educational Studies, 48(1), 76-102.

Buckley, R. C., \& Brough, P. (2017). Economic value of parks via human mental health: an analytical framework. Frontiers in Ecology and Evolution, 5, 1-9.

Christensen, K. M., Holt, J. M., \& Wilson, J. F. (2013). The relationship between outdoor recreation and depression among older adults. World Leisure Journal, $55(1), 72-82$.

Conlon, C. M., Wilson, C. E., Gaffney, P., \& Stoker, M. (2018). Wilderness therapy intervention with adolescents: Exploring the process of change. Journal of Adventure Education and Outdoor Learning, 18(4), 353-366.

Cox, D. T., Shanahan, D. F., Hudson, H. L., Fuller, R. A., Anderson, K., Hancock, S., \& Gaston, K. J. (2017). Doses of nearby nature simultaneously associated with multiple health benefits. International Journal of Environmental Research and Public Health, 14(2), 1-13.

Cozolino, L., \& Sprokay, S. (2006). Neuroscience and adult learning. New Directions for Adult and Continuing Education, 2006(110), 11-19.

Daloz, L. A. (1990). Mentorship. In Michael W. Galbraith (Ed.), Adult learning methods: A guide for effective instruction. Malabar, FL: Robert E. Krieger Publishing Company. 
Derby, M. W., Piersol, L., \& Blenkinsop, S. (2015). Refusing to settle for pigeons and parks: Urban environmental education in the age of neoliberalism. Environmental Education Research, 21(3), 378-389.

Edwards-Jones, A., Waite, S., \& Passy, R. (2018). Falling into LINE: School strategies for overcoming challenges associated with learning in natural environments (LINE). Education 3-13, 46(1), 49-63.

Einstein, A. (2011). The world as I see it. New York, NY: Open Road Media.

Ewert, A. W. (1983). Outdoor adventure and self-concept: A research analysis. Eugene, OR: Center of Leisure Studies.

Ewert, A. W., \& Voight, A. (2012). The role of adventure education in enhancing health-related variables. International Journal of Health, Wellness \& Society, 2(1), 75-87.

Fernee, C. R., Gabrielsen, L. E., Andersen, A. J., \& Mesel, T. (2017). Unpacking the black box of wilderness therapy: A realist synthesis. Qualitative Health Research, 27(1), 114-129.

Finlay, J., Franke, T., McKay, H., \& Sims-Gould, J. (2015). Therapeutic landscapes and wellbeing in later life: Impacts of blue and green spaces for older adults. Health \& Place, 34, 97-106.

Gammage, B. (2011). The biggest estate on earth: how Aborigines made Australia. Sydney: Allen \& Unwin.

Gandy, M. (2016). Unintentional landscapes. Landscape Research, 41(4), 433-440.

Harper, N. J., Gabrielsen, L. E., \& Carpenter, C. (2018). A cross-cultural exploration of 'wild' in wilderness therapy: Canada, Norway and Australia. Journal of Adventure Education and Outdoor Learning, 18(2), 1-17.

Heilig, G. K. (2012). World urbanization prospects: The 2011 revision. New York, NY: United Nations.

Hickman, M., Stokes, P., Beard, C., \& Inkster, A. (2017). Doing the plastic fantastic: 'artificial' adventure and older adult climbers. Journal of Adventure Education and Outdoor Learning, 1-11. https://doi.org/10.1080/14729679.2017.1308874

Holroyd, A. E. M. (2007). Interpretive hermeneutic phenomenology: Clarifying understanding. Indo-Pacific Journal of Phenomenology, 7(2), 1-12. 
Huynh, T. \& Torquati, J. C. (2019). Outdoor adventure instructors' perceptions of nature and their work: a phenomenological study, Journal of Adventure Education and Outdoor Learning, 19(3), 269-282.

Jiang, B., Li, D., Larsen, L., \& Sullivan, W. C. (2016). A dose-response curve describing the relationship between urban tree cover density and self-reported stress recovery. Environment and Behavior, 48(4), 607-629.

Kesebir, S., \& Kesebir, P. (2017). A growing disconnection from nature is evident in cultural products. Perspectives on Psychological Science, 12(2), 258-269.

Kimball, R., \& Bacon, S. (1993). The wilderness challenge model. In M. A. Gass (Ed.), Adventure therapy: Therapeutic applications of adventure programming ( $\mathrm{pp}$. 11-41). Dubuque, IA: Kendall Hunt Publishing Co.

Kotabe, H. P., Kardan, O., \& Berman, M. G. (2017). The nature-disorder paradox: A perceptual study on how nature is disorderly yet aesthetically preferred. Journal of Experimental Psychology: General, 146(8), 1713-1727.

Kowarik, I. (2018). Urban wilderness: Supply, demand, and access. Urban Forestry \& Urban Greening, 29, 336-347.

Langdridge, D. (2007). Phenomenological psychology: Theory, research and method. Harlow, Essex: Pearson.

Larkin, M., Watts, S., \& Clifton, E. (2006). Giving voice and making sense in interpretative phenomenological analysis. Qualitative Research in Psychology, 3(2), 102-120.

Laverty, S. M. (2003). Hermeneutic phenomenology and phenomenology: A comparison of historical and methodological considerations. International Journal of Qualitative Methods, 2(3), 21-35.

Leather, M. (2018). A critique of "Forest School" or something lost in translation. Journal of Outdoor and Environmental Education, 21(1), 5-18.

Lemke, J. (2018). Exploring human nature - A reflexive mixed methods enquiry into Solo time in the wilderness. (Doctoral thesis). Oder: European University Viadrina Frankfurt.

Loeffler, T. (2018). Looking back, paddling forward: perspectives on outdoor expedition participation over the lifespan. Journal of Adventure Education and Outdoor Learning, 1-13. 
Lopez, K. A., \& Willis, D. G. (2004). Descriptive versus interpretive phenomenology: Their contributions to nursing knowledge. Qualitative Health Research, 14(5), 726-735.

McKenzie, M. D. (2000). How are adventure education program outcomes achieved?: A review of the literature. Australian Journal of Outdoor Education, 5(1), 19-28.

Miles, J. (1990). Wilderness. In J. Miles \& S. Priest (Eds.), Adventure education (pp. 325-328). State College, PA: Venture Publishing Inc.

Moran, E. F. (2016). People and nature: An introduction to human ecological relations: John Malden, MA: Wiley \& Sons.

Morgan, A. D. (2010). Journeys into transformation travel to an 'other' place as a vehicle for transformative learning. Journal of Transformative Education, 8(4), 246-268.

Mutz, M., \& Müller, J. (2016). Mental health benefits of outdoor adventures: Results from two pilot studies. Journal of Adolescence, 49, 105-114.

Norðdahl, K., \& Jóhannesson, I. Á. (2016). 'Let's go outside': Icelandic teachers' views of using the outdoors. Education 3-13, 44(4), 391-406.

Norton, C. L., Tucker, A., Russell, K. C., Bettmann, J. E., Gass, M. A., \& Behrens, E. (2014). Adventure therapy with youth. Journal of Experiential Education, 37(1), 46-59.

Patel, V., Flisher, A. J., Hetrick, S., \& McGorry, P. (2007). Mental health of young people: a global public-health challenge. The Lancet, 369(9569), 1302-1313.

Pietkiewicz, I., \& Smith, J. A. (2014). A practical guide to using interpretative phenomenological analysis in qualitative research psychology. Psychological Journal, 20(1), 7-14.

Plager, K. (1994). Hermeneutic phenomenology: a methodology for family health and health promotion study in nursing. In P. Benner (Ed.), Interpretive phenomenology: Embodiment, caring, and ethics in health and illness (pp. 6583). Thousand Oaks, CA: Sage.

Pryor, A., Carpenter, C., \& Townsend, M. (2005). Outdoor education and bush adventure therapy: A social-ecological approach to health and wellbeing. Australian Journal of Outdoor Education, 9(1), 3-13.

Rantala, T., \& Määttä, K. (2012). Ten theses of the joy of learning at primary schools. Early Child Development and Care, 182(1), 87-105. 
Russell, R., Guerry, A. D., Balvanera, P., Gould, R. K., Basurto, X., Chan, K. M., . . Tam, J. (2013). Humans and nature: how knowing and experiencing nature affect well-being. Annual Review of Environment and Resources, 38, 473-502.

Rutko, E. A., \& Gillespie, J. (2013). Where's the Wilderness in Wilderness Therapy? Journal of Experiential Education, 36(3), 218-232.

Schmidt, L. K. (2016). Understanding hermeneutics. London: Routledge.

Scrutton, R., \& Beames, S. (2015). Measuring the unmeasurable: Upholding rigor in quantitative studies of personal and social development in outdoor adventure education. Journal of Experiential Education, 38(1), 8-25.

Singer, J. E. (2018). Being and becoming: the creative balance of the artist teacher. (Doctoral dissertation). Aberdeen: University of Aberdeen.

Smith, J. A., Flowers, P. \& Larkin, M. (2009). Interpretative phenomenological analysis: Theory, method and research. London: Sage.

Smith, J. A., \& Osborn, M. (2015). Interpretative phenomenological analysis as a useful methodology for research on the lived experience of pain. British Journal of Pain, 9(1), 41-42.

Smith, M. (2007). Wild-life: anarchy, ecology, and ethics. Environmental Politics, 16(3), 470-487.

Smith, T. (2005). Going outside to go inside: Frameworks for the solo experience. In C. Knapp \& T. Smith (Eds), Exploring the power of solo, silence, and solitude (pp. 3-18). Boulder, CO: Association for Experiential Education.

Torquati, J., \& Ernst, J. A. (2013). Beyond the walls: Conceptualizing natural environments as 'third educators'. Journal of Early Childhood Teacher Education, 34(2), 191-208.

Ungar, M., Dumond, C., \& McDonald, W. (2005). Risk, resilience and outdoor programmes for at-risk children. Journal of Social Work, 5(3), 319-338.

van Manen, M. (1997). Researching lived experience: Human science for an action sensitive pedagogy London, ON: The Althouse Press.

van Manen, M. (2016). Phenomenology of practice: Meaning-giving methods in phenomenological research and writing. New York, NY: Routledge.

van Manen, M. (2017). But is it phenomenology? Qualitative Health Research, 27(6), $775-779$. 
Walsh, V., \& Golins, G. (1976). The Exploration of the Outward Bound Process. Denver, CO: Colorado Outward Bound School.

White, M. P., Pahl, S., Wheeler, B. W., Depledge, M. H., \& Fleming, L. E. (2017). Natural environments and subjective wellbeing: Different types of exposure are associated with different aspects of wellbeing. Health \& Place, 45, 77-84.

Wolfe, P. (2006). The role of meaning and emotion in learning. New Directions for Adult and Continuing Education, Summer, 2006(110), 35-41.

Zeivots, S. (2015). Lived experience of emotional highs in experiential learning (Doctoral dissertation). Sydney: University of Technology Sydney.

Zeivots, S. (2016). Emotional highs in adult experiential learning. Australian Journal of Adult Learning, 56(3), 353-373.

Zeivots, S. (2018). Triggers of emotional highs in experiential learning. Journal of Adventure Education and Outdoor Learning, 18(3), 275-288.

Zinn, J. O. (2008). Heading into the unknown: Everyday strategies for managing risk and uncertainty. Health, Risk \& Society, 10(5), 439-450. 